\title{
Reducing Inequalities within Countries: Assessing the Potential of the Sustainable Development Goals
}

Lucas Chancel

World Inequality Lab at the Paris School of Economics (PSE) and Institute for Sustainable Development and International Relations (IDDRI)

Alex Hough

Institute for Sustainable Development and International Relations (IDDRI)

Tancrède Voituriez

Institute for Sustainable Development and International Relations (IDDRI) and French Agricultural Research Centre for International Development (CIRAD)

\section{Abstract}

Income and wealth inequality are rising in most countries around the world today. Recognising that this challenge has become a universal issue, the United Nations agreed in 2015 to seventeen Sustainable Development Goals (SDGs), as part of a global agenda to transform society. Specifically, SDG Target 10 commits countries to 'reduce inequalities within and among countries'. To what extent SDGs and in particular SDG target 10 can help nations reverse inequality towards a downward trend is the question we address in this paper. To answer this question, we build on the theory of change underpinning the goal-based governance characterising the SDGs, then we infer the added value of the SDGs along three criteria: the production of a common metric, the capacity to emulate peer pressure, and policy learning within and across countries. Across these three criteria, our main finding is that there is much that states can take away from the SDGs to address the problem of rising inequality, though success is conditional on achieving the buy-in of key actors and epistemic communities for which domestic inequalities remains a domestic issue and not a global sustainability one.

\section{Policy Implications}

- There is much that states can take away from the SDGs to address the problem of rising inequality, though success is conditional on achieving the buy-in of key actors and epistemic communities for which domestic inequalities remains a domestic issue and not a global sustainability one.

- The first major contribution of the SDGs is the old cliché, 'what gets measured gets done'. The guarantee of standardized, comparable statistics is likely to serve as a catalyst for political action to reduce inequality. At the very least, it serves as an enabler for civil society and other non-government institutions to hold governments to account.

- Second, and relatedly, the SDGs create a forum in which countries' performances are ranked against each other. The SDGs enable us to distinguish between those countries that are performing well and those falling behind, while serving to remind political leaders that inequality reduction is not just necessary but possible.

- If a country ranking will be technically feasible thanks to national statistical reports on SDGs, it remains politically tricky. Ranking countries according to their performance in achieving specific goals and targets is very unlikely to become part of the mandate of the UN High Level Political Forum (HLPF). This ranking, which according to us is a key lever for national action, could be produced instead by coalitions of think tanks and research institutions outside of the UN system.

- Greater focus is required to encourage and vitalise the learning process beyond current state practice at HLPF where the risk of 'showcasing' national strategies and anecdotal successes cannot be discarded. Forums cannot simply serve as platforms for states to selectively clarify their individual successes while overshadowing and exonerating responsibility in areas where they have underperformed. Creating a platform for countries successfully implementing corrective measures is therefore vital. 
Income and wealth inequality are rising in most countries around the world today. Recognising that this challenge has become a universal issue, the United Nations agreed in 2015 to 17 Sustainable Development Goals (SDGs), as part of a global agenda to transform society. Specifically, SDG Target 10 commits countries to 'reduce inequalities within and among countries'. To that end, the SDG framework calls on states to articulate nationally specific implementation strategies and to put in place monitoring and review processes in order to meet the goals.

So far, country responses have been sporadic and inconsistent, and there has been little articulation about what Target 10 means in terms of national-level implementation. Reducing inequality between countries - that is to say, increasing the national income of poor countries relatively quicker than rich countries - has been at the core of development thinking for decades and motivated the creation of dedicated institutions such as the International Development Association (1960, as part of the World Bank Group) and UNCTAD (1964). More recently, rising inequality within countries, with an overall increase in top income and wealth shares particularly in highincome countries like Britain and the United States, combined with significant increases in the coverage of available data, have brought to light the need to consider within-country distributional outcomes. However, it is less immediately apparent what role an international framework can and should play in mediating within-country inequality. While some contributing factors like tax evasion, for example, readily lead to the need for a coordinated response between countries, other factors, like national taxation and social spending, are considered as domestic issues traditionally outside the remit of international governance frameworks. To what extent SDGs and in particular SDG target 10 can help nations reverse inequality towards a downward trend is the question we address in this paper.

To answer this question, we proceed in four steps. First, we review the substantive reasons why within-country inequality has become a global sustainable development issue (section 1), and we detail the political process it underwent to become a stand-alone SDG target (section 2). We build on the theory of change underpinning the SDGs to set up a framework of analysis and infer the added value of the SDGs (section 3). Applying this framework to SDG target 10, we provide an assessment of the potential contribution of SDGs to inequality reduction within countries (section 4). We conclude by delineating consistency gaps which would need to be bridged to significantly increase the contribution of SDGs to domestic income and wealth inequality reduction. Our main finding is that there is much that states can take away from the SDGs to address the problem of rising inequality, though success is conditional on achieving the buy-in of key actors and epistemic communities for which domestic inequalities remains a domestic issue and not a global sustainability one.

\section{Why inequality has become a universal sustainable development issue}

After decades of divergence across countries per capita income, there is evidence of convergence at the global level since the 1990s, and in particular since the 2000s (Bourguignon, 2015; Milanovic, 2010; Stiglitz, 2013). Global convergence between rich and poor countries has been driven by Asian countries, first China and India, and now the whole Asian region, where incomes have risen rapidly relative to advanced economies. However, much remains to be done: incomes in Asia remain a quarter of those in the developed world, and convergence has been largely absent or fragile outside of Asia. Latin American and the Caribbean have shown more recent signs of income growth over the last decade, while Africa and Oceania have contributed little to global convergence. On average, in 1990, Africans earned $12 \%$ of the developed country income when adjusted for PPP; this figure remained the same in 2014 (Julca et al., 2015).

\section{A universal issue}

Uneven economic convergence across countries occurred alongside an unprecedented rise in inequality within countries (Atkinson et al., 2011; Piketty and Saez, 2014). Drawing on the new World Wealth and Income Database (WID.world, 2017), we present the evolution of top 1 per cent income shares - a telling metric of inequality - in developed economies and developing economies alike. The extent of the increase varies across countries, but in nearly all nations, the general tendency is one of rising top 1 per cent income shares since the late 1970s (Figure 1). In the USA, the top 1 per cent fiscal income share was close to 10 per cent 40 years ago, and is now above 20 per cent. Over the same period, top 1 per cent fiscal income share increased from 6.5 per cent to 13 per cent in China (Figure 2).

\section{Inequality as a health problem}

Cross-sectional studies show a robust and statistically significant positive correlation between inequality and incidences of health and social problems in advanced countries (see for example Wilkinson and Pickett, 2009). Wilkinson and

Figure 1. Top $1 \%$ fiscal income share in developed economies.

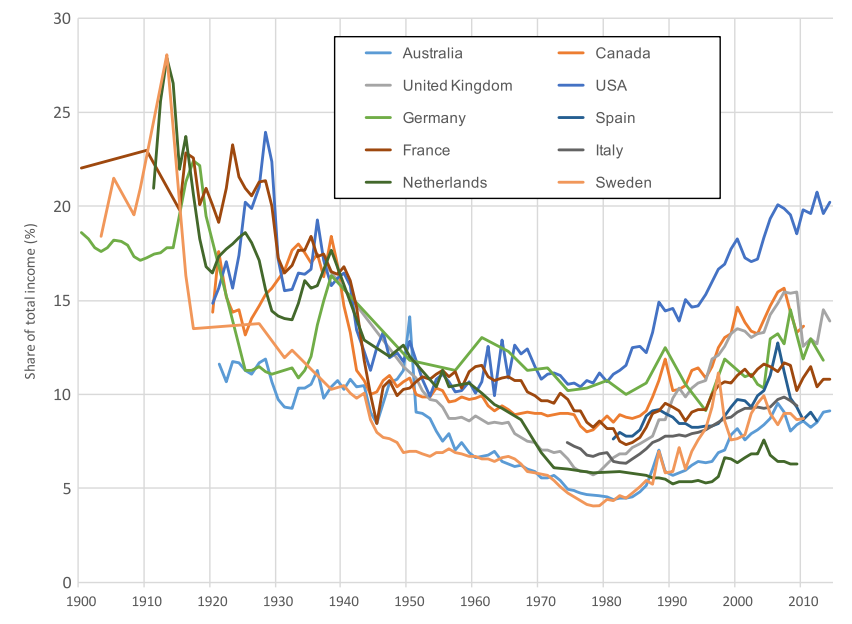

Source: WID.world 
Figure 2. Top 1\% fiscal income share in developing and emerging countries.

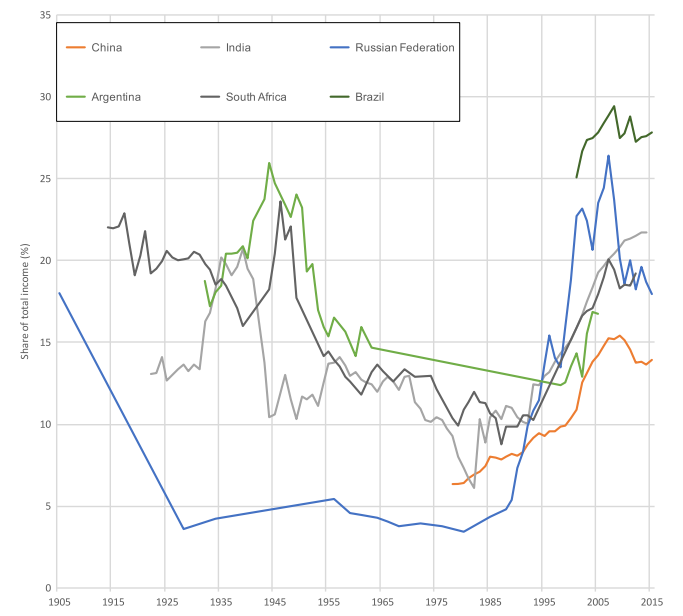

Source: WID.world

Pickett's prominent work, The Spirit Level, aggregates bi-variate analyses for a range of dependent variables pertaining to health and social problems. As summarised in the postscript to the second edition, they find that 'when people in the same social class, at the same level of income or education, are compared across countries, those in more equal societies do better' (Wilkinson and Pickett, 2010, 275-276). More recent work has attempted to establish causality. In a review of the literature, Wilkinson and Pickett find that the major epidemiological causal criteria are 'well supported' and that, therefore, 'narrowing the gap will improve the health and wellbeing of populations' (Wilkinson and Pickett, $2010,316)$. On health, causality between inequality and health problems is relatively well supported, though it is understood to operate indirectly, through 'status anxiety', which may explain why individual level studies find ambiguous results (Bergh et al., 2016). On the other social problems, causality is harder to establish, owing in part to the lack of clear understanding about the causal mechanism through which inequality impacts society (Rowlinson, 2011).

However, even without the assurance of causality, the robust correlation between inequality and the incidence of health and social problems is highly consistent with the integrated SDG approach, which seeks to reinforce positive interactions across the goals.

\section{Inequality as an economic problem}

Multiple studies support that inequality has a negative impact on growth (Cingano, 2014; Ostry et al., 2014). Measured by the Gini index, the impact of inequality on growth is significant. In OECD countries, a one-point decline in the Gini index would translate to an increase in cumulative growth of 0.8 per cent per year for the following 5 years (Cingano, 2014). Furthermore, inequality as measured by the Gini coefficient is a significant explanatory variable of the duration of growth spells: Ostry et al. (2014, p. 23) find that 'a one-Gini-point increase in inequality is associated with a 6 percentage point higher risk that the spell will end the next year'. Dabla-Norris et al. (2015) have shown that a relative rise in top quintile incomes has a negative long-term impact on growth, while growth in the bottom quintile is highly correlated with growth. This corroborates similar results produced by the OECD, that shows that the changes in the bottom quantile as a fraction of the mean are robust and statistically significant explanatory variables of national growth (Cingano, 2014).

The effect of inequality on growth can operate through multiple channels. First, the societal problems associated with inequality incur explicit remedial costs that would not otherwise have been incurred if inequality were less severe. For example, The Equality Trust (2014) estimated that, if the UK reduced inequality so that of the OECD average, expenditure savings on physical and mental illness, violence and imprisonment alone would amount to $£ 39$ billion per year. Second, inequality harms growth by reducing disadvantaged groups' access to public goods (Stiglitz, 2013). In a regression analysis framework focusing on all OECD countries, Cingano (2014) find that the negative impact of inequality on growth is essentially due to lesser access to education for disadvantaged groups, as well as to the reduced quality of education for a given year of school enrolment. This inequality in access to quality education reduces individual capabilities throughout their lifetime, and leads, in turn, to a decline in the productivity of the economy as a whole. Third, inequality can harm growth through reducing motivation at work. Using randomised control trials, Fehr et al. (2009) in Switzerland and Breza et al. (2015) in India showed that pay inequality has strong and significant impacts on labour productivity: more precisely, workers paid more than their peers do not produce more than the average, while workers paid less exhibit a strong reduction (about 30 per cent in the Swiss case). In a similar vein, Card et al. (2012) show that wage inequality affects job satisfaction in California. Fourth, low income households have a higher marginal propensity to consume compared to high income households. Increase in inequality thus tends to reduce overall consumption growth (Johnson et al., 2006).

\section{Inequality as a political problem}

Multiple channels provide possible explanations for a link between inequality and political instability. First, the power of the wealthy extends to a measurable degree of influence in the law. Through multivariate analysis of the United States, Gilens and Page (2014, p. 564) find that 'economic elites and organised groups representing business interests have substantial independent impacts on US government policy, while average citizens and mass-based interest groups have little or no independent influence'. Second, McCarty et al. (2002) study the relationship between political polarisation and inequality in the USA, through several decades of congressmen's vote records and opinion polls. They show that polarisation decreased with inequality in the first part of the 20th Century and rose with it from the mid-1970s onwards. Polarisation makes the Republican Party more pro-rich and less likely to adopt inequality 
reduction policies. A more polarised political system is also said to be less likely to adopt transpartisan, lasting policies.

In line with the polarisation channel, a recent study shows that individuals with stagnant incomes over the past decades in the USA and major European countries are more likely than others to support right wing political parties and hold negative view on immigration (Dobbs et al., 2016). The causes for right wing political support are indeed diverse but such results could support the claim that rising inequalities are challenging the foundations of open parliamentary democracies (Stiglitz, 2013).

\section{Inequality as an environmental problem}

Several studies suggested a link between inequality and environmental quality via two causal channels. The 'Veblen effect' channel posits that the more unequal societies, the more individuals consume to differentiate themselves from other social groups. The mechanism of consumption as a way to mark a certain lifestyle has been relatively well established (Heffetz, 2011). Bowles and Park (2005) show that more unequal countries are countries where people work more and argue that this is due to a Veblen effect: lower ranked individuals work more to replicate the lifestyle of higher ranked individuals. When dominant lifestyles are unsustainable - which is the case, the overall environmental of such consumption dynamics is negative.

The other channel through which inequality impacts on environmental quality was introduced above: unequal societies are more polarised societies, in which agreement on trans-partisan policies (such as environmental policies) is more complicated. Inequality renders more difficult the agreement on and the implementation of environmental policies (Hourcade, 2013; Laurent, 2014), such as carbon taxes. In addition, it has been argued that elites can, at least for a certain amount of time, protect themselves from environmental degradation (Boyce, 2007). That being said, empirical studies on inequality and the environment offer mixed results. While theoretical links can be convincing, more work is required to fully understand the extent of the problem raised by inequality on environmental degradation.

It should also be noted that inequality reduction can nonetheless be negative for the environment: when achieved through income growth at the bottom end of the distribution, it can lead to higher overall pollution levels. At the individual level, income is positively linked with carbon emissions (Lenglart et al., 2010; Lenzen et al., 2006; Wier et al., 2001). Therefore, under current production and consumption patterns, inequality reduction achieved through the growth of incomes among low earners would counteract carbon mitigation efforts at national and global scale (Chancel and Piketty, 2015).

\section{How inequality reduction has become part of the global policy agenda}

In developing a response to rising inequality, policy makers and academia have sought to identify the drivers of inequality. A vast literature posits and tests theoretical drivers of inequality, and of subsequent policy areas to address these drivers (for an overview of this literature, see for example, Atkinson, 2015). The sheer scale of existing literature on this subject suggests that inaction does not derive from a knowledge-gap. After a decade of landmark research, coverage and quality of available data on global inequality have expanded significantly (Milanovic, 2013; WID.world, 2017). Though much remains to be learned, to a significant extent, the core drivers of inequality are known, and can guide policy response.

It has been common to divide the drivers of inequality into categories, first between technology and globalisation (for example, Katz and Autor, 1999) and then, more recently, between technology and trade openness viewed in concert, and policies and institutions (for example, Milanovic, 2016; OECD, 2011). These distinctions are partly artificial and can be, at times, misleading. The nature and extent of technological innovation and openness are, to a large extent, determined by policies and institutions, and the effect of both factors is itself contingent on national-level policies and institutions (Atkinson, 2015; Mazucatto, 2013). We therefore endorse the view of Atkinson (2015) and others that, based on the knowledge that we have about the drivers of inequality, the response to rising inequality should be framed around policies and institutions.

International development institutions have, until recently, paid limited attention to domestic inequality issues, considering the reduction of inequalities as a sovereign issue for each country, or positing inequalities as a necessary evil towards global improvement of wellbeing. Domestic income inequalities have been politically confined in the shadow of absolute poverty until the SDGs replaced the Millennium Development Goals (MDGs, see de Albuquerque, 2012; Kabeer, 2010; Langford, 2010). Until then, the few appearances of domestic inequalities in the global development agenda had narrowed them to inequalities of opportunities and access - without any significant mention of income or wealth (World Bank, 2006).

In this context, the unanimous endorsement of SDG Target 10.1 by the UN Member States marks an important shift. Target 10.1 explicitly includes domestic inequality reduction in the global development agenda. It states: 'By 2030, progressively achieve and sustain a reduction in income inequality, as measured by the share of the bottom 40 percent of the population in national income, alongside economic growth'.

The target was the subject to harshly contested debates in the Open Working Group in charge of establishing a list of goals and targets for intergovernmental negotiations. There were calls for a target for reducing income inequality within countries, measured by the Gini coefficient or the Palma index (Engberg-Pedersen 2013). Meanwhile, the report of the High-Level Panel argued against a target for addressing domestic income inequality on the grounds that 'countries differ widely both in their view of what levels of income inequality are acceptable and in the strategies they adopt to reduce it.' (HLP, 2013, p. 16) Several countries such as the USA and Canada contended that a standalone goal on inequality could 'lead to a sterile debate' and that domestic 
inequality reduction would better be achieved through other goals such as economic growth or a fair access to productive assets. Other countries like China and Indonesia argued that within-country inequalities objectives tended to place a higher burden on developing countries than on OECD economies, and that 'promoting equality should not be a standalone goal area.' (Chancel and Voituriez, 2015).

After the target was removed from the draft-list in the course of 2014, a group of countries led by Denmark, Norway, and Brazil supported its re-inclusion. Denmark, along with Norway, argued that the rise in inequalities found its roots in 'exclusive growth' and that a specific metric should be used to ensure that growth resorbs inequalities rather than triggers them. As for Brazil, while stressing the need to reduce between-country inequalities, it also supported the inclusion of domestic inequality reduction targets. This second group of countries was successful in including the domestic target in the final list, after campaigns from NGOs and lobbying from influential academia such as Stiglitz (Doyle and Stiglitz, 2014).

\section{Inferring the added value of SDGs: A framework for analysis}

While there are diverse narratives explaining how and why the SDGs were set up, the core idea is that they were designed to fill an implementation gap (Caballero, 2015; SDSN, 2015). The 2030 Agenda calls for countries to develop action plans from their existing national sustainable development strategies and to align their policies with the SDGs and associated targets.

Though the theory of change underpinning the SDGs is not explicit when reading the Agenda 2030, it sits in a clear lineage of 'goal setting' development strategies starting with the new public management principles across public administration in OECD countries in the 1980s, and also in the wake of the MDGs 20 years later. Young (2017) recalls that goal setting seeks to steer behavior by: (1) establishing priorities; (2) galvanising the efforts of those assigned to work toward attaining the goals; (3) identifying targets and providing yardsticks or benchmarks to be used in tracking progress; and (4) combating the tendency for short-term desires and impulses to distract the attention or resources of those assigned to the work of goal attainment. He then infers that devising a clear-cut metric is both a requirement and expected outcome of goal-setting as a governance strategy. Following Young (2017), we identify the provision of a harmonised metric as the first contribution of SDGs to fostering action.

Furthermore, Young (2017, p. 34) makes a distinction between goal-setting and rule-making:

The essential premise of goal setting as a governance strategy (...) differs from the premise underlying rule making. Whereas rule making features the formulation of behavioral prescriptions (for example, requirements and prohibitions) and directs attention to matters of compliance and enforcement, goal setting features the articulation of aspirations and directs attention to procedures for generating enthusiasm among supporters and maximizing the dedication needed to sustain the effort required to reach more or less well-defined targets. Moreover, whereas goal setting normally features the mounting of a campaign designed to attain goals within a specified time frame, rulemaking features the articulation of behavioral prescriptions expected to remain in place indefinitely.

This distinction is particularly important in the case of the SDGs which do not contain legally binding compliance and enforcement mechanisms. Instead, what is implicitly expected is that '(o)nce the goals are established, efforts to attain goals normally proceed in campaign mode' (Young, 2017, p. 33).

In concrete terms, the kind of campaign that can be expected to foster the achievement of goal 10 and its associated targets cannot easily be prescribed. The theories of change of campaigners would deserve a paper in its own right. Nonetheless, some key principles to direct the campaigns can be articulated. To that end we draw on a recent paper which distilled key principles for a theory of change in the broad field of development (Valters, 2015). Valters posits that theories of change serve to support learning. Following Young et al. (2015), the purpose of learning in this context is in being 'accountable, improving operations, readjusting strategy, strengthening capacity, understanding the context, deepening understanding (research), building and sustaining trust, lobbying and advocacy and sensitising for action' (Valters, 2015, p. 9). The MDGs - that proceeded the SDGS reflect these principles: decisive in focusing policies, financing and campaigns, the first series of development goals radically changed donors' conception of development, instilling the idea of development as a trial-and-error process on the various means for a given end - the MDG list (Banerjee and Duflo, 2011). The simplicity of the targets that set absolute goals served as a strong conduit for state action and guided international funding organisations. Furthermore, the goals created a simple narrative, triggering self-fulfilling prophecies; they imagined a future of 'zero hunger', 'half the number of people in extreme poverty' and in doing so they shifted expectations and spread the idea that achieving the goals was not only necessary but - and more importantly - possible. We infer that policy learning across countries is another keystone of the theory of change underpinning the SDGs.

Another lesson from the MDGs is that a comparison of countries' performance is made possible by the existence of a harmonised metric. Some leading scholars denounced the MDGs on the ground that they were unfair for Sub-Saharan African countries precisely because ranking countries became an immediate by-product of the MDG targets matrix (Easterly, 2007). On the other hand, one could argue that because the SDGs were negotiated by all countries (which was not the case for the MDGs which were set by donor countries), the mere possibility of ranking them becomes an implicit driver for change. 
The education survey known as the Program for International Student Assessment (PISA) is enlightening regarding the impact of international rankings. Without exaggerating its virtues, PISA has had an influence on the development of education policies in the majority of developed countries (Breakspear, 2012) for several reasons: ranking promotes exchanges between policymakers and experts and allows the strategies of leading countries in an area to be used for comparative studies (including between countries with similar socioeconomic characteristics); it legitimises ongoing reforms (for example the UK has used the PISA ranking to support reforms outlined in its national strategy); it strengthens the quality of national assessments (expansion of the scope of evaluation, further improvement of indicators, etc.); and it enables policy decisions to be better informed according to national and international requirements (Scotland viewed the PISA ranking as a way to measure its relative decline and to influence policy decisions, while focusing on the national context) (Breakspear, 2012). Peer pressure is the third keystone of the theory of change underpinning the SDGs.

\section{Assessing SDGs contribution to policy change}

We assess the specific contribution of the SDG to bridging the policy implementation gap on inequality. We ask what the practical tools offered by the SDG framework (common metric, peer review, and peer learning) can effectively contribute to fill the implementation gap in the case of income and wealth inequality. We also identify areas where the 2030 agenda falls short in terms of filling the implementation gap. Finally, we outline the conditions under which the utility of the SDG can be realised, and suggest options for state and non-state actors to realise these conditions and leverage the existing framework (Table 1).

\section{Do the SDGs provide a common metric to track inequality?}

The 2030 Agenda calls for an extensive set of global indicators in its outcome document (UN, 2015) that would be 'simple yet robust, address all SDGs and targets including for means of implementation.' The framework, the resolution notes, requires that there be 'timely, reliable, and disaggregated data to support the implementation of the ambitious 2030 Agenda'.

A common set of 230 indicators was agreed in 2016 at UN level as the backbone of monitoring the SDGs at local, national, regional, and global levels. They will serve as a management tool to help countries develop implementation strategies and allocate resources accordingly, and as a report card to measure progress towards achieving a target and to ensure the accountability of governments and other stakeholders for achieving the SDGs.

Target 10 satisfies the broad principles of the SDG framework to develop action plans from existing national sustainable development strategies. Over the past decades, an increasing number of countries have adopted so-called 'beyond GDP' indicators to complement GDP and better measure social, environmental and broader economic factors. A close look at national beyond-GDP initiatives shows that inequality featured prominently among them prior to the finalisation of the SDGs (Chancel et al., 2015). The additional value of the SDGs, in this context, is to provide a common, universal metric. The metric carries particular weight as it has been unanimously endorsed by the UN Member States.

That said, the metric for measuring inequality in Target 10.1 has potential descriptive drawbacks. By ensuring that the bottom 40 per cent does not lose out, the target clearly reflects the SDG principle to 'leave no one behind'. However, the indicator is blind to changes at the apex of the distribution (in situations where top earners' and bottom earners' incomes grow while the middle shrinks, for instance). This amounts to more than an innocuous oversight. Rising top income shares drove income inequality dynamics in the past decades (Atkinson et al., 2011; Piketty, 2014).

Table 2 shows the performance of three countries (China, France, USA) on the SDG target, over the past 15 years (2000-2015 period) and in the longer run (1980-2015, time span with available and comparable data). The table revises previous results by Chancel and Voituriez (2015). In the earlier results, including a more extensive list of countries, the results showed that countries variously passed and failed the SDG test over different periods. In the updated data, all three countries considered failed to meet the SDG target 10.1 , suggesting that the target is more ambitious than previously assumed. Still, the target remains feasible. France came very close to achieving the target over the 1980-2015 period, for example. In France, over the 1980-2015 period, the bottom 40 per cent is not far from average growth but the top 0.1 per cent earners enjoy a growth rate that is more than five times higher. In China and the USA as well, the gap between average growth rate and top 0.1 per cent income growth rate (respectively 776 per cent vs. 2,271 per cent and 70 per cent vs. 343 per cent for the 1980-2015 time period) shows the need to complement the bottom 40 per cent target.

We therefore suggest that countries interested in inequality reduction employ a complementary statistic, comparing, when available, the evolution of top incomes (top 1 per cent or top 0.1 per cent income shares) to average growth, in order to capture important changes at the apex of the income distribution. The use of complementary metrics, in addition to the global indicators list adopted by the General Assembly, is explicitly foreseen in the SDG framework. Paragraph 75 of Transforming Our World: The Agenda 2030 for Sustainable Development states: 'The Goals and targets will be followed-up and reviewed using a set of global indicators. These will be complemented by indicators at the regional and national levels which will be developed by member states, in addition to the outcomes of work undertaken for the development of the baselines for those targets where national and global baseline data does not yet exist' (UN, 2015). The inclusion of complementary statistics is voluntary, 


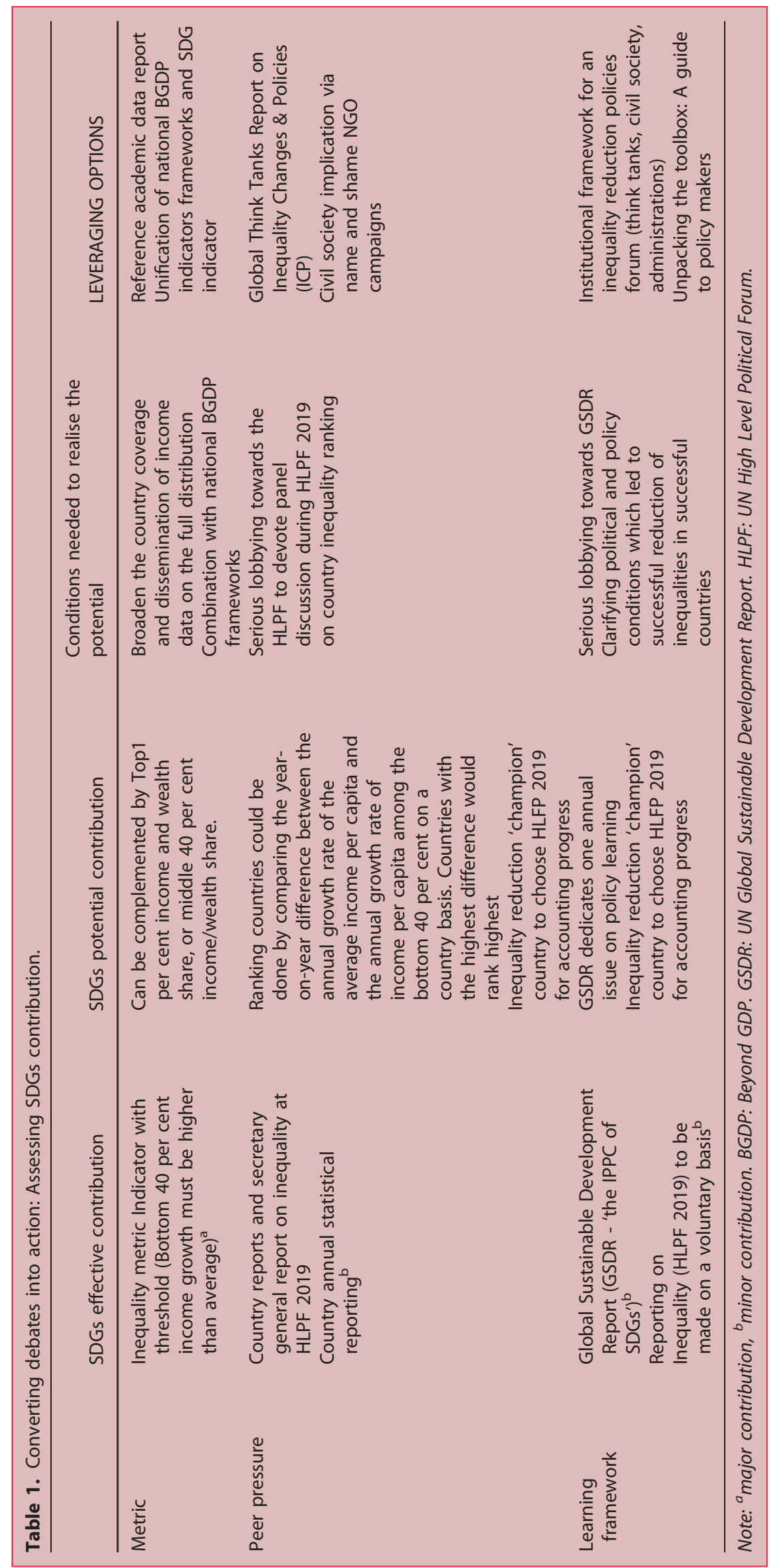


Table 2. Growth and inequality in China, France and USA.

\begin{tabular}{llllllll}
\hline & \multicolumn{5}{c}{$\begin{array}{l}\text { Per adult pre-tax income total } \\
\text { growth (\%) }\end{array}$} & SDG \\
\cline { 3 - 6 } & & Bottom & Top & Top & & \\
Country & Period & $40 \%$ & $1 \%$ & $0.1 \%$ & Average & \\
\hline China & $1980-2015$ & 332 & 1800 & 2271 & 776 & FAIL \\
& $2000-2015$ & 182 & 379 & 450 & 257 & FAIL \\
France & $1980-2015$ & 17 & 84 & 155 & 32 & FAIL \\
& $2000-2015$ & -4 & 38 & 82 & -1 & FAIL \\
USA & $1980-2015$ & 0.4 & 221 & 343 & 70 & FAIL \\
& $2000-2015$ & -6 & 22 & 31 & 10 & FAIL \\
\hline
\end{tabular}

Sources: WID.world (2017). Note: growth in pre-tax per adult income. Authors' computations. Key: Average per adult income of the bottom 40 per cent group increased by 332 per cent in China over the 1980-2015 period. Average per adult growth rate was 776 per cent over the period. All figures are net of inflation.

based on the discretion of states. In this case, epistemic communities have already contributed a great deal: data about the income and wealth of the top 1 per cent produced by academia and civil society have been harnessed by activists and NGOs to increase awareness in the issue of rising inequality. The uptake of this complementary indicator will therefore depend on the continued participation of civil society actors and academia.

Table 3 informs us on another important dimension of the debate: the source of data used to check whether countries meet the SDG objective is crucial. In Table 3, we compare the data source used in Table 2 (coming from WID.world, which combines fiscal sources and surveys), with survey data from the World Panel on Income Distribution (Lakner and Milanovic, 2013).

The main insight from this comparison is that growth rates vary substantially according to the two sources. The USA would pass the test according to Lakner and Milanovic data over 1988-1998 while it clearly does not qualify in the WID.world source. In this example, the survey data does not capture all income growth in the US in 1988-1998, particularly at the top of the distribution.

How best tackle the data source issue, given that the UN has so far not provided specification on data source types that member states should use (UN, 2017)? Survey data is well-known for its inability to capture top income dynamics in a satisfactory way, because of underreporting and undersampling issues (Atkinson and Bourguignon, 2015). Additionally, in the case of the widely used World Panel on Income Distribution (Lakner and Milanovic, 2013), the surveys variously refer to consumption and to income. The level of consumption inequality is always lower than income inequality because of differential in savings rates across households. Mixing the two concepts is thus problematic.

The SDG test will need to be based on standardised and comparable concepts of income. The most promising way to deal with data limitation seems to reconcile within a harmonised framework the different sources available, namely tax data, national accounts and household surveys (Alvaredo et al., 2016). This is the approach which pursued at WID. world.

\section{Can SDGs create peer pressure and increase political will for change?}

The SDGs indicator not only provides a harmonised metric, it also sets a threshold for the income growth of the bottom 40 per cent. The monitoring is carried out through an annual reporting system, under the aegis of the UN Secretary General, based on indicators and national statistics. Nothing in Target 10.1 constrains the speed of inequality reduction, nor the optimal range of outcomes that countries should aim to achieve. Nevertheless, to reach the target, several countries in the developed and developing world will have to invert current inequality trends (Chancel and Voituriez, 2015).

Increasing inequality can reflect the preference (or indifference) of a given society, even though it is intrinsically contrary to its own interests, as discussed in the first section of this paper. How preferences and interests are shaped and

Table 3. Who is virtuous? On the importance of data source used.

\begin{tabular}{|c|c|c|c|c|c|c|c|}
\hline \multirow[b]{3}{*}{ Country } & \multirow[b]{3}{*}{ Period } & \multicolumn{3}{|c|}{ WID.world Dataset } & \multicolumn{3}{|c|}{ Lakner-Milanovic Dataset } \\
\hline & & \multicolumn{2}{|c|}{ Pre-tax income growth (\%) } & \multirow[b]{2}{*}{ SDGTest } & \multicolumn{2}{|c|}{ Survey income growth (\%) } & \multirow[b]{2}{*}{ SDG Test } \\
\hline & & Bottom $40 \%$ & Full population & & Bottom $40 \%$ & Full population & \\
\hline \multirow[t]{2}{*}{ China } & 1988-1998 & -0.2 & 19 & FAIL & 24 & 73 & FAIL \\
\hline & $1998-2008$ & 55 & 118 & FAIL & 44 & 145 & FAIL \\
\hline \multirow[t]{2}{*}{ France } & 1988-1998 & 5 & 13 & FAIL & 65 & 17 & PASS \\
\hline & $1998-2008$ & 8 & 11 & FAIL & 28 & 30 & FAIL \\
\hline \multirow[t]{2}{*}{ USA } & 1988-1998 & 5 & 22 & FAIL & 19 & 13 & PASS \\
\hline & $1998-2008$ & 2 & 11 & FAIL & 5 & 25 & FAIL \\
\hline
\end{tabular}

Source: WID.world (2017) and World Panel on Income Distribution (Lakner and Milanovic, 2013). Authors' computations. Note: WID.world is based on consistent combination of tax, survey and national accounts data; the figures report the evolution of pre-tax per adult national income. The Lakner and Milanovic Dataset reports survey data on income or on consumption. 
evolve over time is a question which has spurred passionate debates in social sciences. The bedrock of our approach is that additional knowledge on the state of the problem and on the solutions space contributes to altering preferences and the distribution of interests across stakeholders likely to influence the policy process. The success of this approach depends on multiple factors. Many countries - and OECD countries in particular - have for many years submitted their national sustainable development strategies to the critical scrutiny of other countries ('peer reviews'), but these assessments have only had a limited influence on national policy. It is indeed particularly difficult to satisfy the conditions necessary for these peer reviews to have an impact: high-level political commitment, adequate budgetary resources, involvement of non-state actors, and timeliness, among other factors (Vaillé and Brimont, 2016). While acknowledging these limitations, we nonetheless assume in the following paragraphs that the dissemination of the pass and fail tests enabled by Target 10.1 . is likely to trigger peer pressure that leads to action at the national level.

Is PISA-like ranking conceivable within the SDG framework? PISA benefits are maximised when stakeholders recognise the indicators as legitimate, when monitoring and reporting mechanisms are in place - as planned in the 2030 Agenda - and when evaluation results are disseminated to the media (McGee and Gaventa, 2010). The political appeal of ranking is particularly striking during national election campaigns - at least among EU 27 countries. In particular, GDP growth, unemployment rate and public spending as a share of GDP have pervaded continental Europe in national debates on welfare state reforms over the last two decades. Beyond-GDP-indicators which have been developed and included in the national jurisdiction of a few countries rest on a similar rationale of country-to-country comparison (Chancel et al., 2014). The interactive OECD Better Life Index tool for instance enables people 'to express what matters most to them (...), share and compare their answers with people across 38 OECD member and non-member countries' (OECD, 2016).

Practically, ranking countries could be done by comparing the year-on-year difference between the annual growth rate of the average income per capita and the annual growth rate of income per capita among the bottom 40 per cent on a country basis. Countries with the highest difference would rank highest.

Table 4 encapsulates year-on-year values of target 10.1 and top 1 per cent per adult pre-tax income growth for China, France and the US, from 2010 to 2013 (last available year-on-year WID.world data) and for year 1999-2000. It provides four snap-shots of countries' performance on the official (bottom 40 per cent, 'Test 1') and complementary (top 1 per cent, 'Test 2') inequality targets and makes a ranking of countries along the bottom 40 per cent income convergence speed, as well as along the gap between average and top 1 per cent growth. Looking at what dub the Test 1, China ranked first in 2011 and 2012 and passed the SDG test, but failed in 2013. The other way round, the US failed in 2011 and 2012 but topped in 2013, displaying sharp year-on-year changes in inequality pattern. Test 2 shows that the ranking of countries can be modified when focusing on top 1 per cent income growth rather than bottom 40 per cent. In 1999-2000 for instance, France passes Test 1 but fails on Test 2 .

Country ranking will be technically feasible thanks to national statistical reports on SDGs. We must be clear however that it remains politically tricky. Ranking countries according to their performance in achieving specific goals and targets is very unlikely to become part of the mandate of the UN High Level Political Forum (HLPF). This ranking could be produced instead by coalitions of Think Tanks,

Table 4. Ranking countries along target 10.1 year-on-year values.

\begin{tabular}{|c|c|c|c|c|c|c|c|c|c|c|}
\hline \multirow[b]{2}{*}{ Country } & \multirow[b]{2}{*}{ Period } & \multirow[b]{2}{*}{$\begin{array}{l}\text { Full pop.- } \\
\text { income } \\
\text { growth (\%) }\end{array}$} & \multicolumn{4}{|l|}{ Test 1} & \multicolumn{4}{|l|}{ Test 2} \\
\hline & & & $\begin{array}{l}\text { Bottom } 40 \% \text { - } \\
\text { income } \\
\text { growth(\%) }\end{array}$ & $\begin{array}{l}\text { Difference to } \\
\text { full pop. (P.P) }\end{array}$ & $\begin{array}{l}\text { SDG } \\
\text { Test }\end{array}$ & Rank & $\begin{array}{l}\text { Top1\%- } \\
\text { Income } \\
\text { growth (\%) }\end{array}$ & $\begin{array}{l}\text { Difference } \\
\text { to full } \\
\text { pop (P.P.) }\end{array}$ & $\begin{array}{l}\text { SDG } \\
\text { Test }\end{array}$ & Rank \\
\hline USA & $2012-2013$ & 0.0 & 3.9 & 3.9 & PASS & 1 & -5.7 & 6 & PASS & 2 \\
\hline France & & -0.2 & 2.7 & 2.9 & PASS & 2 & -14.6 & 14 & PASS & 1 \\
\hline France & & -2.7 & -2.1 & 0.6 & PASS & 2 & -3.1 & 0 & PASS & 2 \\
\hline USA & & 2.2 & -0.3 & -2.5 & FAIL & 3 & 8.4 & -6 & FAIL & 3 \\
\hline China & 2010-2011 & 7.2 & 9.7 & 2.5 & PASS & 1 & 3.4 & 4 & PASS & 1 \\
\hline France & & 3.7 & 0.4 & -3.3 & FAIL & 2 & 28.0 & -24 & FAIL & 3 \\
\hline USA & & 1.5 & -1.9 & -3.4 & FAIL & 3 & 0.4 & 1 & PASS & 2 \\
\hline France & 1999-2000 & 2.7 & 2.7 & 0.0 & PASS & 1 & 5.1 & -2 & FAIL & 1 \\
\hline
\end{tabular}

Source: WID.world (2017). Income growth rates correspond to real per adult pre-tax national income. Figures corrected for inflation. Authors computations. 
research institutions and civil society organisations (CSO) outside of the UN system. Some initiatives are underway. Taking a comprehensive approach of the SDGs, the SDSN has developed a SDG index and dashboard for country ranking (SDSN, 2016). The Migration and Development Civil Society Network (MADE) in cooperation with Cordaid has drafted 'Proposals for Shadow Reporting on SDG implementation' (MADE, 2015). Transparency International issued a methodological note for SDG shadow reporting questionnaire to 'help assess progress towards three SDG targets linked to anti-corruption and government transparency' and make comparisons across countries (Transparency International, 2017). In this context there both a clear need and a space for inequality ranking across countries that could be filled by the economic inequality and environmental inequality communities together.

\section{Can SDGs provide a platform for learning?}

A third contribution of SDGs in converting policy discourses into action is the opportunity they provide to compare policy performance across countries, and learn from both successes and failures. The simple fact of providing a platform for comparison of countries' performance and to derive applicable policy solutions in different contexts does not guarantee that this process will take place, as it depends to a large extent on political will. Recent evidence from climate change policies tend to suggest that countries can learn from one another and reduce their own risk aversion toward sustainable development policies (Colombier, 2015; Henry and Tubiana, forthcoming). By making the case that reducing inequality is feasible, one country's success can elicit political traction in another country and realise the ambition of the 2030 Agenda to make SDG implementation a genuine experimentation process.

There are already dedicated platforms to enable mutual learning among countries. At the opening of the 2016 High-Level Political Forum (HLPF) on the Sustainable Development Goals, Under-Secretary-General Wu Hongbo commented that 'the lessons you have offered, the actions you have showcased, and the gaps you have identified, they are what this Forum is about: advancing the SDGs through sharing of experiences, and mutual learning' (UNDESA, 2016). The Forum included SDGs Learning, Training and Practice sessions 'providing capacity building, networking and experience-sharing opportunities on crucial topics related to the implementation of the 2030 Agenda'.

The issue of inequality is highly suited to this kind of platform. An expanding literature has identified an extensive range of national level policy responses that states may adopt in addressing high or rising inequality, and furthermore, many countries have successfully implemented policies to reduce inequality. Some preeminent examples, like the case of Chile since the middle of the 2000s, offer scope for learning and adoption by other countries and the sustainable development platform provides a dedicated platform to that end (Martinez-Aguilar et al., 2017). Examples such as the case of Chile where fiscal interventions covering a wide range of instruments also support a process of South-North learning. It is hoped that such a process would increase the buy-in for the broader goals among countries in the Global South.

However, much remains to be done to increase the functionality of the mutual learning process - of genuine peer learning. Greater focus is required to encourage and vitalise the learning process beyond current state practice at UN HLPF which is overly permissive of countries 'showcasing' national strategies and anecdotal successes, as it was the case at the time of the UN Commission on Sustainable Development which preceded the HLPF. Forums cannot simply serve as platforms for states to boast about their individual successes while overshadowing and overlooking areas of inaction or underperformance. Building on Chancel et al. (2017), we thus propose: (1) the publication of an annual statistical and policy report ranking countries over their performance on SDG target 10.1. This report could include contributions from academia but should eventually be endorsed by the United Nations Statistical Agency. G20 countries could take the lead on this; (2) this report would contain - or would be supplemented by a side-report on a discussion of successful and less successful policies implemented in different countries to tackle inequality and (3) the report would be presented and discussed at an annual global inequality conference. These conferences could be kickstarted by civil society, the academia or G20 hosts, but they should be eventually organised by the United Nations.

\section{Conclusion}

Rising economic inequality within countries is a defining challenge of our time. A growing body of literature highlights the negative impacts of domestic inequality on a wide number of political, social, economic and environmental problems - thus rendering domestic inequality a key sustainable development challenge. However, over the past decade, despite growing concern, debates have not been converted into action and domestic inequality keeps rising.

The inclusion of inequality within the Sustainable Development Goals framework shows that the United Nation Member States are formally committed to tackle this problem. One can wonder however what could be the effective contribution of a United Nations process which does not have any binding mechanism. What comes out of our research is that the SDGs provide three levers to turn the global inequality debate into action: peer focus (a common metric), peer pressure (a ranking of countries) and peer review (mutual learning of policies). The contribution of SDGs to each of these levers is however not equal. While the common metric exists, only significant involvement from civil society, epistemic communities which were more concerned so far with domestic economic debates surrounding inequality, and the commitment from governments will make it possible for peer pressure and learning to become effective. These three effective and potential contributions of SDG stand out as necessary conditions to transform the 
global inequality debate into action. But they are not sufficient: in particular, the relationship between SDGs and international trade, investment deals and fiscal agreements will also need to be clarified - replacing such discussions at the centre of the policy agenda is another potential side-effect of the SDG impetus.

\section{References}

Alvaredo, F., Atkinson, T., Chancel, C., Piketty, T., Saez, E. and Zucman, G. (2016) 'Distributional National Accounts Guidelines', working paper, 2016/2. WID.world. Paris.

Atkinson, A. B. (2015) Inequality: What Can Be Done. Cambridge, MA: Harvard University Press.

Atkinson, A. B. and Bourguignon, F. (2015) Handbook of Income Distribution, , Volume 2A. Amsterdam: Elsevier.

Atkinson, A. B., Piketty, T. and Saez, E. (2011) 'Top Incomes in the Long Run of History', Journal of Economic Literature, 49 (1), pp. 3-71.

Banerjee, A. V. and Duflo, E. (2011) Poor Economics. New York: Public Affairs.

Bergh, A., Nilsson, T. and Waldenström, D. (2016) Sick of Inequality. Cheltenham: Edward Elgar.

Bourguignon, F. (2015) The Globalization of Inequality. Princeton, NJ: Princeton University Press.

Bowles, S. and Park, Y. (2005) 'Emulation, Inequality, and Work Hours: Was Thorsten Veblen Right?' The Economic Journal, 115 (507), F397-F412.

Boyce, J. K. (2007) 'Is Inequality Bad for the Environment?' Working Paper No. 135. Political Economy Research Institute. University of Massachussets: Amherst.

Breakspear, S. (2012) 'The Policy impact of PISA: an exploration of the normative effect of international benchmarking in school system performance'. OECD Education Working Paper number 71 - OECD Publishing.

Breza, E., Kaur, S. and Shamdasani, Y. (2015) 'The morale effect of pay inequality'. NBER Working Paper 22491. NBER, Cambridge, MA.

Caballero, P. (2015) 'A short history of the SDGs' [online]. Available from: http://deliver2030.org/wp-content/uploads/2016/04/A-short-historyof-the-SDGs-Paula-Caballero.pdf [Accessed 13 October 2017].

Card, D., Mas, A., Moretti, E. and Saez, E. (2012) 'Inequality at Work: The Effect of Peer Salaries on Job Satisfaction', American Economic Review, 102 (6), pp. 2981-3003.

Chancel, L., Hough, A. and Voituriez, T. (2017). 'Towards a PISA-type ranking on economic inequality' [online]. Available from: http://www. g20-insights.org/policy_briefs/towards-pisa-type-ranking-economicinequality/ [Accessed 13 October 2017].

Chancel, L. and Piketty, T. (2015) 'Carbon and Inequality: From Kyoto to Paris Trends in the Global Inequality of Carbon Emissions (1998-2013) \& Prospects for an Equitable Adaptation Fund', Paris School of Economics, 3rd November [online]. Available from: http://piketty.pse.ens.fr/files/ChancelPiketty2015.pdf [Accessed 13 October 2017].

Chancel, L., Thiry, G. and Demailly, D. (2014) 'Beyond-GDP Indicators: To What End ? Lessons Learnt from Six National Experiences' Issue Brief 4/2014. Paris: International Institute for Sustainable Development and International Relations.

Chancel, L. and Voituriez, T. (2015) 'Taking Income Inequality Reduction Seriously: A Pass-or-fail Test for the Sustainable Development Goals', Issue Brief 06/2015. Paris: International Institute for Sustainable Development and International Relations.

Cingano, F. (2014) 'Trends in Income Inequality and its Impact on Economic Growth', Social, Employment and Migration Working Paper No. 163. Paris: OECD Publishing.

Colombier, M. (2015) 'COP21: Building an Unprecedented and Sustainable Agreement', Iworking paper 13. Paris: International Institute for Sustainable Development and International Relations.
Dabla-Norris, E., Kochhar, K., Ricka, F., Suphaphiphat, N. and Tsounta, E (2015) 'Causes and consequences of income inequality: A global perspective', Staff Discussion Note 15/13. IMF. Washington: DC.

De Albuquerque, C. (2012) 'The Future Is Now: Eliminating Inequalities in Sanitation, Water and Hygiene'. Report by the United Nations Special Rapporteur on the human right to safe drinking water and sanitation, October 2012. United Nations. New York.

Dobbs, R., Madgavkar, A., Manyika, J., Woetzel, J., Bughin, J., Labaye, E. and Kashyap, P. (2016). Poorer than their parents? A new perspective on income inequality. Rotman Management Magazine: The Inequality Issue, Fall, pp. 63-68.

Doyle, M. and Stiglitz, J. (2014) 'Eliminating Extreme Inequality: A Sustainable Development Goal, 2015-2030', Ethics \& International Affairs [online], 28 (1). Available from: https://www.ethicsandinterna tionalaffairs.org/2014/eliminating-extreme-inequality-a-sustainable-de velopment-goal-2015-2030/ [Accessed 13 October 2017].

Easterly, W. (2007) 'How the Millennium Development Goals are Unfair to Africa'. Washington: Brookings.

Engberg-Pedersen, L. (2013) 'Development Goals Post 2015: Reduce Inequality,' Policy Brief, April 2013. Copenhagen: Danish Institute for International Studies.

Fehr, E., Goette, L. and Zehnder, C. (2009) 'A behavioral account of the labor market: The role of fairness concerns', Annual Review of Economics, 1, pp. 355-384.

Gilens, M. and Page, B. I. (2014) 'Testing Theories of American Politics: Elites, Interest Groups, and Average Citizens', Perspectives on Politics, 12 (3), pp. 564-581.

Heffetz, O. (2011) 'A test of conspicuous consumption: Visibility and income elasticities', The Review of Economics and Statistics, XCIII(4), pp. 1101-1117.

Henry, C. and Tubiana, L. (forthcoming) Earth at Risk. Natural Capital and the Quest for Sustainability. New York: Columbia University Press.

Hourcade, J. C. (2013) 'Killing the Carbon Tax with the Equity Argument: Lessons from the Sarkozy Tax' In Genevey, R., Pachauri, R.K. and Tubiana L. (eds) (2013) Reducing Inequalities: a sustainable development challenge. Teri Press, New Delhi, India, pp. 157-168.

Johnson, D., Parker, J. and Souleles, N. (2006) 'Household expenditure and the income tax rebates of 2001', American Economic Review, 96 (5), pp. 1589-1610.

Julca, A., Hunt, N. and Alarcón, D. (2015) 'Income convergence or persistent inequalities among countries?', Development Issues [online] No. 5. UN/DESA 26 October 2015. Available from: https://www.un. org/development/desa/dpad/publication/no-5-income-convergence-orpersistent-inequalities-among-countries/ [Accessed 13 October 2017].

Kabeer, N. (2010) 'Can the MDGs Provide a Pathway to Social Justice? The Challenge of Intersecting Inequalities', New York: Institute of Development Studies (IDS)/United Nations Development Programme (UNDP.

Katz, L. F. and Autor, D. H. (1999) 'Changes in the Wage Structure and Earnings Inequality'. In Ashenfelter, O. and Card, D. (eds.) Handbook of Labor Economics, volume 3. Amsterdam: North Holland, pp. 14631555.

High Level Panel (2013) A New Global Partnership. United Nations [online]. Available from: http://www.post2015hlp.org/the-report/ [Accessed 19 October 2017].

Lakner, C. and Milanovic, B. (2013) 'World Panel Income Distribution (LM - WIPD)'. Washington, DC: The World Bank.

Langford, M. (2010) 'A Poverty of Rights: Six Ways to Fix the MDGs', IDS Bulletin 41 (1), pp. 83-89.

Laurent, É. (2014) 'Inequality as pollution, pollution as inequality: The social-ecological nexus', Stanford Center on Poverty and Inequality working paper [online]. Available from: https://web.stanford.edu/ group/.../laurent_inequality-pollution.pdf [Accessed 13 October 2017].

Lenglart, F., Lesieur, C. and Pasquier, J.-L. (2010) 'Les émissions de CO2e du circuit économique en France'. Report. Paris: INSEE. 
Lenzen, M., Wier, M., Cohen, C., Hayami, H., Pachauri, S. and Schaefer, R. (2006) 'A comparative multivariate analysis of household energy requirements in Australia, Brazil, Denmark, India and Japan', Energy, 31 (2-3), pp. 181-207.

McGee, R. and Gaventa, J. (2010) 'Review of Impact and Effectiveness of Transparency and Accountability Initiatives'. Synthesis Report, Institute of Development Studies.

MADE (2015) 'Proposals for shadow reporting on SDG implementation', draft outline [online]. Available from: madenetwork.org/sites/default/ files/160309_Revised_Outline_CSO_Shadow_Report_for_SDG_implementation.docx [Accessed on 16 October 2017].

Martinez-Aguilar, S., Fuchs, A., Ortiz-Juarez, E. and Del Carmen, G. (2017) 'The Impact of Fiscal Policy on Inequality and Poverty in Chile' [online]. Policy Research working paper; no. WPS 7939. Washington, D.C. Available from: http://documents.worldbank.org/curated/en/ 924981484072376329/The-impact-of-fiscal-policy-on-inequality-andpoverty-in-Chile [Accessed 16 October 2017].

Mazzucato, M. (2013) 'The Entrepreneurial State: Debunking Public vs. Private Sector Myths'. London: Anthem Press.

McCarty, N., Poole, K. T. and Rosenthal, H. (2002) 'Political Polarization and Income Inequality', Working Paper 201. Russell Sage Foundation. New York City.

Milanovic, B. (2010) The Haves and the Have Nots: A Brief and Idiosyncratic History of Global Inequality. New York: Basic Books.

Milanovic, B. (2016) Global inequality: A new approach for the age of globalization. Cambridge, MA: Harvard University Press.

OECD (2011) Divided we Stand. Why Inequality Keeps Rising. Paris: OECD Press.

OECD (2016) 'How's Your Life and What Matters Most to You? Going Beyond GDP'. OECD Insights. Debate the Issues. 2 June 2016. Paris: OECD.

Ostry, J. D., Berg, A. and Tsangarides, C. G. (2014) 'Redistribution, Inequality, and Growth', Staff Discussion Note 14/02.IMF: Washington, DC.

Piketty, T. (2014) Capital in the XXth Century. Cambridge, MA: Harvard University Press.

Piketty, T. and Saez, E. (2014) 'Inequality in the long run', Science 344 (6186), pp. 838-843.

Sustainable Development Solutions Network (SDSN 2015) 'Getting Started with the Sustainable Development Goals'. Available from: http://unsdsn.org/wp-content/uploads/2015/12/151211-getting-sta rted-guide-FINAL-PDF-.pdf [Accessed July 2016].

SDSN (2016) 'SDG Index \& Dashboards. A Global Report', July 2016. Sustainable Development Solution Network \& Bertelsmann Stiftung [online]. Available from http://sdgindex.org/\#full-report. [Accessed 16 October 2017].

Stiglitz, J. (2013) The Price of Inequality: How Today's Divided Society Endangers Our Future. New York: W.W. Norton and Company.

The Equality Trust (2014) 'The Cost of Inequality' [online]. Available from: https://www.equalitytrust.org.uk/cost-inequality-0 [Accessed 16 October 2017].

Transparency International (2017) 'Methodological note for SDG shadow reporting questionnaire' [online]. Available from: https://www.transpa rency.org/whatwedo/publication/methodological_note_for_sdg_shad ow_reporting_questionnaire (Accessed 31 May 2017).

UN (2015). Transforming Our World: The Agenda 2030 For Sustainable Development. UN General Assembly 21 October 2015 A/RES/70/1.

UN (2017) 'UN SDG Indicators Global Database' [online]. Available from : https://unstats.un.org/sdgs/indicators/database/?indicator=10.1.1 (Accessed 31 May 2017).

UNDESA (2016) 'Advancing SDGs Through Sharing of Experiences and Mutual Learning [online]. Available from: https://sustainabledeve lopment.un.org/?page =view\&nr=1111\&type $=230 \&$ menu $=2059$ [Accessed 16 October 2017].

Vaillé, J. and Brimont, L. (2016) 'Turning Sustainable Development Goals into political drivers, in France and other European countries', Policy Brief 02/2016. Paris: International Institute for Sustainable Development and International Relations.

Valters, C. (2015) 'Theories of Change. Time for a radical approach to learning in development'. London: ODI.

WID.world, (2017) 'World Wealth and Income Database' [online]. Available from: www.wid.world [Accessed 28 May 2017].

Wier, M., Lenzen, M., Munksgaard, J. and Smed, S. (2001) 'Effects of Household Consumption Patterns on CO2e Requirements', Economic Systems Research, 13 (3), pp. 259-274.

Wilkinson, R. and Pickett, K. (2009) The Spirit Level: Why More Equal Societies Almost Always Do Better. London: Allen Lane.

Wilkinson, R. and Pickett, K. (2010) The Spirit Level: Why More Equal Societies Almost Always Do Better, 2nd edn. London: Allen Lane.

Young, J., Shaxson, L., Jones, H., Hearn, S., Datta, A. and Cassidy, C. (2015) ROMA: A Guide to Policy Engagement and Influence. London: ODI.

Young, O. (2017) 'Conceptualization: Goal-setting as a Strategy in Earth System Governance', in Kanie, N. and Biermann,F. (eds.). Governing through Goals. Sustainable Development Goals as Governance Innovation. Cambridge, MA: The MIT Press, pp. 31-52.

\section{Author Information}

Lucas Chancel is Co-Director of the World Inequality Lab at the Paris School of Economics and Senior Research Fellow at the Institute for Sustainable Development and International Relations. He also teaches at Sciences Po.

Alex Hough has a Master's degree in international development from Sciences Po's Paris School of International Affairs. His research interest is in inequality and global governance.

Tancrède Voituriez is director of the Governance Program at the Institute for Sustainable Development and International Relations and senior research fellow at the French Agricultural Research Centre for International Development. He also teaches at Sciences Po.

His research focus on sustainable development financing and tradeinduced inequality. 